\title{
Extraction of Nickel Nanoparticles from Electroplating Waste and Their Application in Production of Bio-diesel from Biowaste
}

\author{
Abhishek Kumar Sharma, Sameerah Desnavi, Charu Dixit, Utkarshaa Varshney, and Ankur Sharma
}

\begin{abstract}
Electroplating waste samples were collected from various nearby industries in Aligarh, Uttar Pradesh (India), a prominent place for these industries and it was found that the concentrations of $\mathrm{Cr}^{+6}, \mathrm{Ni}^{+2}, \mathrm{Cu}^{+2}$ and $\mathrm{Zn}^{+2}$ ions were much more than the permissible norms of discharge which causes serious damage to the environment. To cater this issue, these heavy metal ions were extracted from the sample and then converted to their respective oxide nanoparticles by chemical precipitation and sol-gel methods respectively. And then, these nanoparticles were characterized by FTIR and XRD techniques. Also one of the major wastes produced in India is the butchery waste which causes severe health problems and is aesthetically unpleasant. This paper mainly focuses on the production of biodiesel from butchery waste by a new pathway utilizing heterogeneous nano-catalysts of $\operatorname{Nickel}\left(\mathrm{Ni}^{+2}\right)$ (extracted from electroplating waste) for the process of trans-esterification, which produces biodiesel which are mono-alkyl esters of long chain fatty acids (FAME-Fatty Acid Methyl Esters).
\end{abstract}

Index Terms-Electroplating waste, nanoparticles, chemical precipitation, sol-gel, XRD, FTIR, butchery waste, transesterification, biodiesel.

\section{INTRODUCTION}

Due to rapid industrialization, urbanization and rise of living standards, there is a serious increase in environmental pollution. Apart from this, economic and industrial development and growth in Nation's economy, there is a serious need of management and safe disposal of this waste. In cities like Aligarh in Uttar Pradesh (India), where these electroplating, lock, brass-hardware, leather, steel industries are flourishing day by day, the waste produced by them is a problem of global concern. This waste largely contains the heavy metal ions like $\mathrm{Cu}$ (II), $\mathrm{Zn}$ (II), $\mathrm{Cr}$ (VI) and $\mathrm{Ni}$ (II) etc. Till now this heavy metal waste is dumped directly into the environment without any significant scientific treatments [1]. So, it's a very serious issue.

In India, Butchery waste is produced in large quantities especially during the festival of Eid-ul-zuha which causes environmental problems as well as diseases [2]. This waste contains a large amount of triglycerides which can be converted into biodiesel. Biodiesel is technically competitive with conventional, petroleum-derived diesel fuel and requires virtually no changes in the fuel

Manuscript received June 3, 2014; revised October 10, 2014.

The authors are with the Department of Electrical Engineering, ZHCET, Aligarh Muslim University, India (corresponding author: Charu Dixit; email: charu.dixit2310@gmail.com). distribution infrastructure. Other advantages of biodiesel as compared to petro-diesel include reduction of most exhaust emissions, biodegradability, higher flash point, inherent lubricity [2]. Moreover, Production of biodiesel from animal fats is less expensive than traditional methods like extraction of biodiesel from trans-esterification of soyabean oil [3], [4], jatropha, vegetable oils, waste cooking oils [5], [6] etc.

In order to meet these challenges, we had made an attempt for utilizing the electroplating waste for extracting the nanoparticles (heterogenous catalysts) by chemical precipitation and sol-gel method and then using these nanoparticles in production of bio-diesel from the butchery waste [7], [8].

\section{EXPERIMENTAL}

Few samples were collected by us from the nearby industries (names can't be disclosed). These industries generally produce two types of waste:

- The waste produced after Chrome plating,

- The waste produced after Ni plating.

The $\mathrm{pH}$ of chrome plating waste was found to be 0.7 and the $\mathrm{pH}$ of Ni plating waste was found to be 1.5 .

After testing these samples in atomic adsorption spectrophotometer in the Department of Applied Chemistry, AMU, Aligarh, the observation result is shown in Table I. We got very drastic and unbelievable results. The concentration of the heavy metals was found to be thousands times more than the permissible limit set by the Bureau of Indian Standards (BIS).

TABLE I: CONCENTRATION OF HEAVy METAL IONS IN WASTE SAMPLES
\begin{tabular}{|l|l|l|l|l|}
\hline & $\begin{array}{c}\mathrm{Ni}^{+2} \\
(\mathrm{ppm})\end{array}$ & $\begin{array}{l}\mathrm{Cr}^{+6} \\
(\mathrm{ppm})\end{array}$ & $\begin{array}{l}\mathrm{Cu}^{+2} \\
(\mathrm{ppm})\end{array}$ & $\begin{array}{l}\mathrm{Zn}^{+2} \\
(\mathrm{ppm})\end{array}$ \\
\hline $\begin{array}{l}\text { Nickel } \\
\text { plating } \\
\text { waste }\end{array}$ & $\begin{array}{l}30000- \\
40000\end{array}$ & $20-40$ & $5-10$ & $5-8$ \\
\hline $\begin{array}{l}\text { Chrome } \\
\text { Plating } \\
\text { Waste }\end{array}$ & $70-100$ & $\begin{array}{l}80000- \\
120000\end{array}$ & $300-350$ & $150-200$ \\
\hline
\end{tabular}

\section{A. Extraction of $\mathrm{Ni}^{+2}$ Nanoparticles}

$200 \mathrm{ml}$ of the Nickel plating waste sample was treated with $10 \mathrm{M} \mathrm{NaOH}$ solution (prepared by adding $10 \mathrm{~g} \mathrm{NaOH}$ pellets to $100 \mathrm{ml}$ distilled water) till the $\mathrm{pH}$ becomes 8 at about $40{ }^{\circ} \mathrm{C}$ on the heater with magnetic stirrer. $\mathrm{Cu}^{+2}, \mathrm{Zn}^{+2}$ and $\mathrm{Ni}^{+2}$ ions get precipitated. Then to separate out this precipitate from the mixture, the mixture was allowed to 
centrifuge. Then we get the filtrate, which contains $\mathrm{Cr}^{+6}$.

The precipitate that remains after centrifugation is now dissolved in water. Since this mixture is free from Chromium, Nickel can be easily extracted from it. $100 \mathrm{ml}$ of this solution was taken and allowed to react with Dimethyl Glyoxime (prepared by adding $0.2 \mathrm{~g}$ of DMG powder dissolved in $20 \mathrm{ml}$ of Ethanol) (Ethanol taken was $99.9 \%$ pure of the company CHONG YU HI-TECH)). The mixture was continuously stirred at room temperature and DMG is added drop-wise to the mixture to form red precipitate of $\mathrm{Ni}$ $(\mathrm{DMG})_{2}$. The precipitate so obtained is separated by centrifugation and washed. The paste thus obtained is again washed with ethanol and kept in oven at $110{ }^{\circ} \mathrm{C}$ for about 12 hours, red hard mass was obtained.

The red hard mass was grinded mechanically and was kept for calcination in furnace for 4 hours at $450{ }^{\circ} \mathrm{C}$. Greyish white mass now obtained was grinded for about 45 minutes and a fine greyish white powder was obtained. This obtained fine powder was characterized by XRD and FTIR spectroscopy.

\section{B. Preparation of Oil from Butchery Waste}

Samples of butchery waste were obtained from local slaughter houses in Aligarh and were analyzed it was found that when $3 \mathrm{~kg}$ of the solid waste sample was taken in a container in water and kept under constant mechanical stirring at $110{ }^{\circ} \mathrm{C}$ for about $1-2$ hours. $0.5 \mathrm{~kg}$ of oil was obtained after centrifugation, floating at the top. The oil sample was then separated using decantation. The density of oil obtained was $0.75 \mathrm{~g} / \mathrm{cm}$ (by performing simple mathematical calculations)

The characteristics of oil so obtained are:

TABLE II: CHARACTERISTICS OF OBTAINED OIL

\begin{tabular}{|l|l|}
\hline FFA Content & $2.5 \mathrm{gm}$ \\
\hline Flash Point & $206^{\circ} \mathrm{C}$ \\
\hline Cloud Point & $37^{\circ} \mathrm{C}$ \\
\hline Pour Point & $33^{\circ} \mathrm{C}$ \\
\hline Refractive Index & $1.47158\left(\right.$ At $\left.16.96^{\circ} \mathrm{c}\right)$ \\
\hline
\end{tabular}

\section{Trans-Esterification/Production of Biodiesel}

Biodiesel was produced using base catalyzed Transesterification process [4]-[6]. Sample of $100 \mathrm{ml}$ oil was taken in a beaker and is kept on hot plate magnetic stirrer at a temperature maintained at $55{ }^{\circ} \mathrm{C} .16 \%$ v/v methanol i.e. $6.25 \mathrm{ml}$ was added along with $0.25 \mathrm{~g}$ of $\mathrm{NaOH}$ (obtained from MERCK) and $0.056 \mathrm{~g}(0.75 \mathrm{w} / \mathrm{w} \%)$ of nickel nanoparticles were added in the mixture [9]. The mixture was maintained at $\mathrm{pH}$ of 8.5 and allowed to stir for 70 minutes till two separate layers of biodiesel (FAME) and glycerol were observed.

The obtained sample was kept in separating funnel and about $20 \mathrm{~mL}$ of chloroform was added in the separating funnel to obtain distinct layers of bio-diesel and mixture of nanoparticles with glycerol. Proceeding further, it was washed with water 3 times to remove glycerol, remaining nano-catalysts and other un-reacted chemicals settling the bio-diesel at the bottom of the funnel. Bio-diesel was collected by pouring the bottom layer in beaker. It was heated to remove excess water from the bio-diesel.

\section{RESUlTS AND DISCUSSIONS}

\section{A. Characterization of Nanoparticles}

1) XRD pattern of nickel oxide nanoparticles

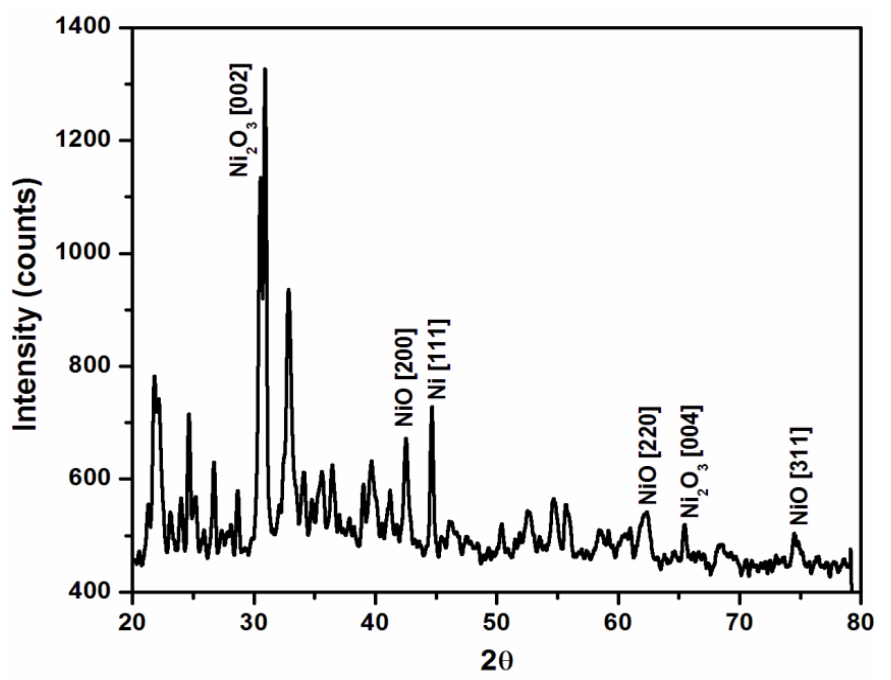

Fig. 1. XRD pattern of Nickel Oxide nanoparticles

The crystalline phase, structure and particle size of Nickel Oxide nanoparticles were obtained by $\mathrm{X}$-ray diffraction (Rigaku-Miniflex) using $\mathrm{Cu}-\mathrm{K}_{\alpha}$ radiations $(\lambda=1.5406 \AA \hat{)})$ in $2 \theta$ range from $20^{\circ}$ to $80^{\circ}$. The average size of the particles was calculated by the Scherrer's formula:

$$
D=\frac{0.9 \lambda}{\beta \cos \theta}
$$

where $\lambda$ is the wavelength of $\mathrm{X}$-ray radiation, $\beta$ is the full width at half maximum (FWHM) of the peaks at the diffracting angle $\theta$. The X-Ray diffraction peaks at $2 \theta$ of $42.52,62.14,74.5$ were identified as peaks of $\mathrm{NiO}$ cubic phase crystallites with various diffraction planes [200], [220], [311]. The other peaks found at an angle (20) of 30.92, 65.48 were identified as $\mathrm{Ni}_{2} \mathrm{O}_{3}$ which corresponds to [002], [004]. A peak observed at $(2 \theta)$ of 44.66 was identified for $\mathrm{Ni}$ [111] [10]. The average size was found to be around 25 nanometer (nm). Hence this result confirmed the formation of Nickel Oxide nanoparticles and some extra peaks shows there is some impurity.

2) FTIR pattern of nickel oxide nanoparticles

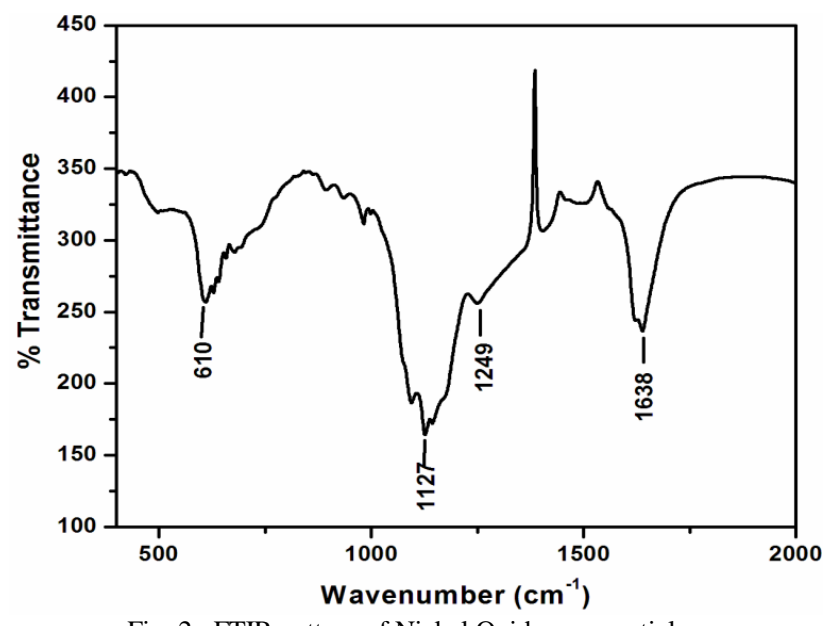

Fig. 2. FTIR pattern of Nickel Oxide nanoparticles.

FTIR spectra were recorded in solid phase using $\mathrm{KBr}$ pellet technique in the region $2000-400 \mathrm{~cm}^{-1}$. FTIR spectra 
of Nickel Oxide nanoparticles are shown in Fig. 2. The band observed at $1638 \mathrm{~cm}^{-1}$ is due to the $\mathrm{OH}$ bending of water. A strong band at $610 \mathrm{~cm}^{-1}$ is assigned to the $\mathrm{Ni}-\mathrm{O}$ stretching band which is consistent with that reported elsewhere confirm the formation of $\mathrm{NiO}$ nanoparticles [11]. Due to adsorption of $\mathrm{CO}$ band at $1127 \mathrm{~cm}^{-1}(\mathrm{C}-\mathrm{O})$ and a symmetric stretching vibration at $1249 \mathrm{~cm}^{-1}\left(\mathrm{COO}^{-1}\right)$ are appeared.

The $\mathrm{Ni}^{+2}$ nanoparticles of size $25 \mathrm{~nm}$ are obtained from the collected electroplating wastes by means of precipitation method followed by sol-gel technique. The extracted $\mathrm{Ni}^{+2}$ nanoparticles are now used as heterogeneous catalysts to increase the available reaction sites for the reactants and decrease the temperature requirement for the process of trans-esterification [5]-[12] for the conversion of pyrolytic oil to get FAME ( fatty acid methyl esters ) known as Biodiesel [5] .

\section{3) FTIR pattern of bio-diesel}

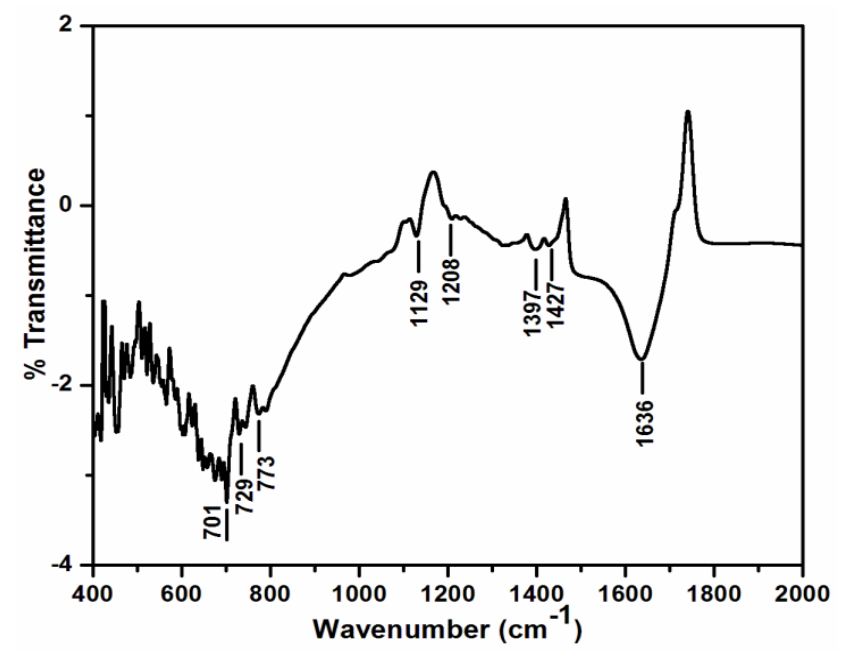

Fig. 3. FTIR pattern of obtained bio-diesel.

FTIR spectra were recorded in liquid phase by mounting the sample in liquid sample holder in the region 2000-400 $\mathrm{cm}^{-1}$. FTIR spectroscopy is very fast and precise method for analyzing bio-diesel. Since, the bio-diesel is mono-alkyl ester, the characteristic peaks of ester in FTIR spectrum due to the presence of $\mathrm{C}=\mathrm{O}$ bond and $\mathrm{C}-\mathrm{O}$ bond were found to be around $1636 \mathrm{~cm}^{-1}$ and $1208 \mathrm{~cm}^{-1}$. Some other peaks were noticed at 701, 729, 773, 1129, 1397, $1427 \mathrm{~cm}^{-1}$ which indicated the conversion of oil into bio-diesel [12].

Initiation of trans-esterification involves abstraction of proton by methanol by the nano-catalysts to form methoxide ion [7]-[15]. The methoxide ion thus created, attacks on carbonyl carbon present in the triglycerides, forming alkoxy carbonyl.

The electroplating waste was successfully converted into nanoparticles of $\mathrm{Ni}^{+2}$ thus one major type of waste that earlier was released into the atmosphere causing severe health problems was utilized to produce very effective nanoparticles that have many applications in various areas.

The another major waste-butchery waste was again converted into very useful and less toxic biodiesel which has many advantages over conventional petroleum fuel [9] and that by a new and more effective method using nanoparticles as catalysts.

Biodiesel produced also has many advantages as it is a renewable source of energy [2]-[8].
Feasibility of this work lies in the idea that it caters to 2 major types of wastes and converts them into biodiesel which is a very useful renewable source of energy and is less toxic.

\section{CONCLUSION}

As per our study, $\mathrm{Ni}^{+2}$ nanoparticles can be extracted easily by means of precipitation followed by sol-gel process from the electroplating waste. These nanoparticles can be used as a catalyst for carrying out trans-esterification reaction using butchery waste [14] in a more efficient and less time consuming manner. It yields high quality biodiesel that has many applications and also is very eco-friendly. This work is solely oriented towards the effective utilization of waste and serves as an example for the "utilization of waste to utilize the waste".

\section{ACKNOWLEDGMENT}

We are very thankful to the Applied Chemistry Department, AMU Aligarh for their guidance and support. Also we are very much grateful to research scholar Mr. M. Mehedi Hassan for his guidance and making various concepts clear.

\section{REFERENCES}

[1] J. W. Patterson, Industrial Waste Water Treatment, Butterworth Science, 1997.

[2] S. T. Hussain, S. A. Ali, A. Bano, and T. Mahmood, "Use of nanotechnology for the production of biofuels from butchery waste," International Journal of the Physical Sciences, vol. 6, no. 31, pp. 7271-7279, November 30, 2011.

[3] Z. Yang and W. Xie, "Soybean oil transesterification over zinc oxide modified with alkali earth metals," Fuel, Processing Technology, Elsevier, vol. 88, pp. 631-638, 2007.

[4] G. Teng, L. Gao, G. Xiao, and H. Liu "Transesterification of Soybean oil to biodiesel over heterogeneous solid base catalyts," Energy and Fuels, vol. 23, pp. 4630-4634, 2009.

[5] R. Guzatto, D. Defferrari, Q. B. Reiznautt, Í. Cadore, and D. Samios, "Transesterification double step process modification for ethyl ester biodiesel production from vegetable and waste oils," Fuel, Elsevier, vol. 92, pp. 197-203, 2012.

[6] A. N. Phan and T. M. Phan, "Biodiesel production from waste cooking oils," Fuel, Elsevier, vol. 87, issue 17-18, pp. 3490-3496, December 2008.

[7] S. Semwal, A. K. Arora, R. P. Badoni, and D. K. Tuli, "Biodiesel production using heterogeneous catalysts," Bioresource Technology, vol. 102, issue 3, pp. 2151-2161, February 2011.

[8] M. Kouzua, T. Kasuno, M. Tajika, Y. Sugimoto, S. Yamanaka, and J. Hidaka "Calcium oxide as a solid base catalyst for transesterification of soybean oil and its application to biodiesel production," Fuel, Elsevier, vol. 87, pp. 2798-2806, 2008.

[9] J. M. Dias, M. C. M. Alvim-Ferraz, M. F. Almeida, J. D. M. Díaz, M. S. Polob, and J. R. Utrilla, "Selection of heterogeneous catalysts for biodiesel production from animal fat," Fuel, Elsevier, vol. 94, pp. 418-425, 2012.

[10] N. Srivastava and P. C. Srivastava, "Realizing NiO nanocrystals from a simple chemical method," Bull. Mater. Sci., vol. 33, no. 6, pp. 653656, December 2010.

[11] J. Li, R. Yan, B. Xiao, D. T. Liang, and D. H. Lee, "Preparation of nano-nio particles and evaluation of their catalytic activity in pyrolyzing biomass components," Energy \& Fuels, vol. 22, no. 1, American Chemical Society, May 2007.

[12] F. Tahira, S. T. Hussain, S. D. Ali, Z. Iqbal, and W. Ahmad, "Homogeneous catalysis of high free fatty acid waste cooking oil to fatty acid methyl esters (Biodiesel)," International Journal of Energy and Power, vol. 1, issue 1, pp. 31-36, August 2012.

[13] J. F. Puna, J. F. Gomes, M. J. N. Correia, A. P. S. Dias, and J. C. Bordado, "Advances on the development of novel heterogeneous catalysts for transesterification of triglycerides in biodiesel," Fuel, Elsevier, vol. 89, pp. 3602-3606, 2010. 
[14] L. Canoira, M. Rodriguez-Gamero, E. Querol et al., "Biodiesel from low-grade animal fat: production process assessment and biodiesel properties characterization," Ind. Eng. Chem. Res., 2008, vol. 47, pp. 7997-8004.

[15] G. Wen, Z. Yan, M. Smith, P. Zhang, and B. Wen, "Kalsilite based heterogeneous catalyst for biodiesel production," Fuel, Elsevier, vol. 89, pp. 2163-2165, 2010.

\begin{abstract}
Abhishek Kumar Sharma was born on July 27, 1992, who had graduated in civil engineering with first division in 2014 from Zakir Husain College of Engineering and Technology, Aligarh Muslim University. His major areas of interest include nanotechnology and environmental engineering. He has published one paper in international journal and 3 papers in international conferences. He had pursued his Summer Internship under the collaboration of Delhi University and Defence Research and Development Organization (DRDO) in 2012 and in National Institute of Disaster Management (NIDM) in 2013. He has won various national and one Asia level paper presentation competitions.
\end{abstract}

Sameerah Desnavi was born on July 2, 1993. She is presently pursing B.Tech degree (final year) in electronics engineering from Zakir Husain College of Engineering and Technology, Aligarh Muslim University. Her major areas of interest include nanotechnology and solid-state electronics and she has published one paper in AIP proceeding in a national conference. She was a summer research intern in High Pressure and Synchrotron Radiation Physics Division (HP\&SRPD), Bhabha Atomic Research Center (BARC,Trombay 2013) and Mobile Robotics, Thinklabs in 2012. She has won prizes in national and Asia level paper presentation. She is a member of IEEE.
Charu Dixit was born on October 23, 1993, who is an electrical engineering final year undergraduate at Zakir Husain College of Engineering and Technology, AMU. Her research interest includes material science, power electronics and electrical machines. She was a summer intern at SEC, Ministry of New and Renewable Energy (GOI) in 2013 and at IOCL refinery in 2014. She has won national and Asia level paper/project presentation competitions and Olympiads.

Utkarshaa Varshney was born on July 28, 1993. She is a final year (B.Tech) electrical major undergraduate, Zakir Husain College of Engineering and Technology, Aligarh Muslim University. She is currently a summer research student at Australian National University, Canberra, Australia in 2014 and was a research intern at Ministry of New and Renewable Energy (MNRE), Govt. of India 2013. She won National and Asia-Level paper presentation competitions. Her fields of interest include nanoengineering, material science, electro-mechanical systems, solar photovoltaics and performance models for PV devices.

Ankur Sharma was born on March 2, 1992, who is majoring in mechanica engineering, final year, at Zakir Husain College of Engineering and Technology, Aligarh Muslim University. He is currently a summer research student at Australian National University, Canberra, Australia in 2014 and was a research intern at Ministry of New and Renewable Energy (MNRE), Govt. of India in 2013. He won in National and Asia level paper presentation competitions. He is a student chairperson at ASME, ZHCET, and an active member of ASME 2014. His research fields of interest include fuels and combustion, material science, automotive engineering, nanoelectronics, electromechanical systems, chemical and bio sensing devices, solar thermal power and refrigeration, optimization of solar thermal technologies, Vapour absorption machines (VAM). 